\title{
Stabilisation of Soybean Oil with Pod Coat Extracts of Cowpea (Vigna unguiculata)
}

Sukriti Nehra, Sushila Singh, Savita Rani

10.18805/LR-4268

\begin{abstract}
Background: In edible oil processing industry the main reason of lipid deterioration is oxidation. The inclusion of antioxidants is required to preserve colour, flavour and to prevent vitamin destruction. In recent years the discovery of safe antioxidants of plant origin have increased conspicuously and they have been considered as better alternative than synthetic antioxidants such as tert-butyl hydroquinone, butylated hydroxyanisole, propyl gallate etc. This study is an attempt to investigate pod coats of cowpea as potential source of natural antioxidants and to appraise their efficacy for stabilizing soybean oil.

Methods: In the laboratory investigation during 2015-2018 the efficacy of cowpea pod coat extracts in stabilizing soybean oil during accelerated storage has been studied. Pod coats of cowpea were extracted with three solvents (acetone, ethyl acetate and chloroform). Soybean oil samples were stabilised by adding different pod coat extracts at 1000 and 2000 ppm concentration.

Result: Our investigation allowed us to conclude that rate of oxidative degradation of soybean oil was the lowest in the sample treated with acetone extract (2000 ppm).
\end{abstract}

Key words: Conjugated dienes, Conjugated trienes, Cowpea, Free fatty acids, Peroxide value, p-Anisidine value.

Abbreviation: ACE- Acetone extract, CFE- Chloroform extract, EAE- Ethylacetate extract.

\section{INTRODUCTION}

Vigna unguiculata (L.) walp (Cowpea) is a widely cultivated legume in Africa, Central and South America and Asia. It is staple food that contains large amount of carbohydrates, proteins, vitamins of $\beta$-complex, essential minerals, dietary fibres and very low level of lipids and anti-nutritional factors (Mtolo et al. 2017). Its seeds are taken as boiled greens or transformed into flour to make different food items. They are rich in bioactive phenolic compounds which includes phenolic acids and flavonoids that are especially concentrated in seed coat and are capable to defend the body against chronic diseases (Awika and Duodu, 2016).

Antioxidants are compounds which prevent autooxidation of fats and oils by donating their hydrogen to the free radicals generated during auto-oxidation. Natural antioxidants can be extracted from low cost resources. In past few decades a lot of researches have been carried out using plant extract in edible oil in place of synthetic additives. Antioxidant prevents free radical induced cell and biological target damage by retarding the formation of radicals, scavenging them or by promoting their decomposition (Young and Woodside, 2001). Currently, edible oil processing industry uses synthetic antioxidants such as butylated hydroxyl toluene (BHT), butylated hydroxyl anisole (BHA), propyl gallate (PG) and tert-butyl hydroquinone (TBHQ) to retard lipid oxidation and prevent development of rancidity in edible oils (Frankel, 1996). However, there is concern about the safety and toxicity of synthetic antioxidants in relation to their metabolism and accumulation in body organs and tissues. In most countries, the usage level of synthetic antioxidants is regulated and the safety of the compounds involved has been tested based on long-term toxicity studies.
Department of Chemistry, College of Basic Sciences and Humanities, CCS Haryana Agricultural University, Hisar-125 004, Haryana, India.

Corresponding Author: Sukriti Nehra, Department of Chemistry, College of Basic Sciences and Humanities, CCS Haryana Agricultural University, Hisar-125 004, Haryana, India.

Email: sukritinehrasn@gmail.com

How to cite this article: Nehra, S., Singh, S. and Rani, S. (2022). Stabilisation of Soybean Oil with Pod Coat Extracts of Cowpea (Vigna unguiculata). Legume Research. DOI: 10.18805/LR-4268.

Submitted: $28-10-2019$

Accepted: 06-12-2021

Online: 04-03-2022

Cowpeas are processed and consumed extensively in developing countries and the large amount of pod coats discarded as waste after threshing may be considered potential sources of phenolic compounds for application as natural antioxidants in foods. Much of the interest on naturally occurring antioxidants is developed because of the trend to minimize or avoid the use of synthetic food additives (Shahidi 2005). The objective of present study was to determine the efficacy of phenolic extracts of pod coats of cowpea in stabilisation of soybean oil.

\section{MATERIALS AND METHODS}

\section{Preparation of extracts and stabilization of oil samples}

The threshed pods of cowpea were taken from the experimental field of CCS HAU Hisar, Haryana and the investigation was conducted in 2018. Pod coats were separated from grass residues and grinded to powder. The 
powdered samples were extracted by petroleum ether $(60-$ $80^{\circ} \mathrm{C}$ ). The defatted $100 \mathrm{~g}$ dried powdered samples were then extracted separately by the soxhlet method using acetone, ethylacetate and chloroform for $8 \mathrm{~h}$. Cowpea pod coat extracts were added to refined SBO at the concentrations 1000 and $2000 \mathrm{ppm}$. Synthetic antioxidant (butylated anisole) was applied at its legal limit (100 and $200 \mathrm{ppm})$. Samples were prepared in triplicate and kept in dark brown bottles and mixed for 25 minutes and then stored $50^{\circ} \mathrm{C}$ in an oven to accelerate the deterioration of the oil. Control samples without antioxidants were also placed under the same storage conditions. The required amounts $(\mathrm{mg})$ of the samples were withdrawn at regular intervals and analyzed for following parameters:

Determination of free fatty acid content of oil samples

Free fatty acids were determined by titrimetric analysis as described by Rao et al. (1972).

\section{Determination of peroxide value (PV) of oil samples}

Peroxide values of oil samples were estimated according to the AOAC official method (1990) and expressed as milliequivalents per kilogram (meq/kg) of sample.

\section{Determination of p-anisidine value (AV) of oil samples}

Formation of secondary oxidation products was measured in terms of $p$-anisidine value. $p$ - anisidine value assay was carried out according to the procedure of AOCS official method (1998).

\section{Determination of Total oxidation (TOTOX) values of oil samples}

Total oxidation (TOTOX) values were calculated according to the method of Shahidi and Wanasundara (2008). Anisidine value is used in conjunction with $\mathrm{PV}$ to calculate total oxidation.

$$
\text { Total oxidation }(\text { TOTOX) value }=2 \mathrm{PV}+\mathrm{p}-\mathrm{AV}
$$

\section{Estimation of Conjugated dienes (CD) and conjugated trienes (CT) in oil samples}

Conjugated diene and conjugated triene of oil samples was assessed according to Frankel method (1962). The conjugated dienes and trienes were expressed as the percentage of conjugated dienoic and trienoic acid.

Determination of carotenoids content in oil samples Carotenoids content was determined by the method of Vasconcellous et al. (1980) and expressed in mg carotene/ $\mathrm{Kg}$ oil sample.

\section{Determination of total tocopherol in oil samples}

Total tocopherol content was determined by the method of Philip et al. (1954) and expressed in $\mathrm{mg} / 100 \mathrm{~g}$ of oil sample.

Determination of Thiobarbituric Acid Value (TBA) of oil samples

Thiobarbituric acid value (TBA) was determined according to the method of Marcuse and Johansson, (1973) with slight modification. Thiobarbituric acid value was expressed as mequiv of malonaldehyde/g of oil sample.

\section{RESULTS AND DISCUSSION}

\section{Effects of additives on free fatty acids content of} soybean oil

FFA contents (\% oleic acid) of the stabilized and control SBO samples, over an incubation period of 28 days at $50^{\circ} \mathrm{C}$ is shown in Fig 1. FFA, which are mainly the product of hydrolysis, often parallel to oxidative damage (McGinely, 1991), increased in a typical fashion. However, result indicates that the addition of BHA played a part in retarding the rancidity of SBO. The FFA content was reduced from $4.223 \pm 0.023 \%$ to $2.519 \pm 0.013 \%$ with BHA (100 ppm), while from $4.223 \pm 0.023 \%$ to $2.009 \pm 0.011 \%$ with $\mathrm{BHA}(200 \mathrm{ppm})$. Addition of extracts also caused a significant reduction in FFA content of SBO. Acetone extract at $2000 \mathrm{ppm}$ concentration showed highest reductionin FFA from $4.223 \pm 0.023 \%$ to $2.861 \pm 0.008 \%$, while chloroform extract at $1000 \mathrm{ppm}$ concentration showed lowest reduction in FFA from $4.223 \pm 0.023 \%$ to $3.735 \pm 0.017 \%$. Results of the present investigation are comparable to the finding of Anwar et al. (2007) regarding oxidative deterioration of SBO at ambient and sunlight storage. FFA content of various samples at the end of storage period was in following order:

Control>CFE $(1000 \mathrm{ppm})>\mathrm{EAE}(1000 \mathrm{ppm})>\mathrm{ACE}(1000$ ppm) $>$ CFE $(2000$ ppm) $>$ EAE (2000 ppm) >ACE (2000 ppm) $>\operatorname{BHA}(100$ ppm)>BHA (200 ppm)

\section{Effects of additives on PV of soybean oil}

$\mathrm{PV}$ of control and stabilized samples are presented in Fig 2. It is evident from the results that the addition of both $\mathrm{BHA}$ and different extracts inhibited the oxidation in SBO significantly as compared to the control. PV of the control sample varied from $3.40 \pm 0.01 \mathrm{meq} / \mathrm{kg}$ to $41.62 \pm 0.05 \mathrm{meq} /$ $\mathrm{kg}$. PV of all the samples increased slowly till $12^{\text {th }}$ day of storage and then rapidly till the end of storage period. PV of the samples containing $\mathrm{BHA}(100$ and $200 \mathrm{ppm})$ were found to be $13.38 \pm 0.03$ and $10.86 \pm 0.02 \mathrm{meq} / \mathrm{kg}$ respectively at the end of the storage period. Among the samples stabilized by different extracts, lowest PV $(28.86 \pm 0.07 \mathrm{meq} / \mathrm{kg})$ was observed in sample containing acetone extract (2000 ppm), while the highest $P V(35.41 \pm 0.03 \mathrm{meq} / \mathrm{kg})$ was observed in sample containing chloroform extract (1000 ppm). The high $\mathrm{PV}$ is due to the formation of unstable hydroperoxides that ultimately converts to short chain acids, aldehydes, ketones and alcohols and thus causes off flavour and odour (Crapiste et al. 1999). The peroxide values of various samples at the end of storage period were found in the following order:

Control>CFE (1000 ppm)>EAE (1000 ppm)>CFE (2000 ppm) >ACE (1000 ppm)>EAE (2000 ppm)>ACE (2000 ppm) $>$ BHA $(100$ ppm $)>\operatorname{BHA}(200$ ppm $)$

\section{Effects of additives on AV of soybean oil}

The results of $A V$ of SBO samples supplemented with $B H A$ or pod coat extracts are shown in Fig 3. Estimation of $A V$ 


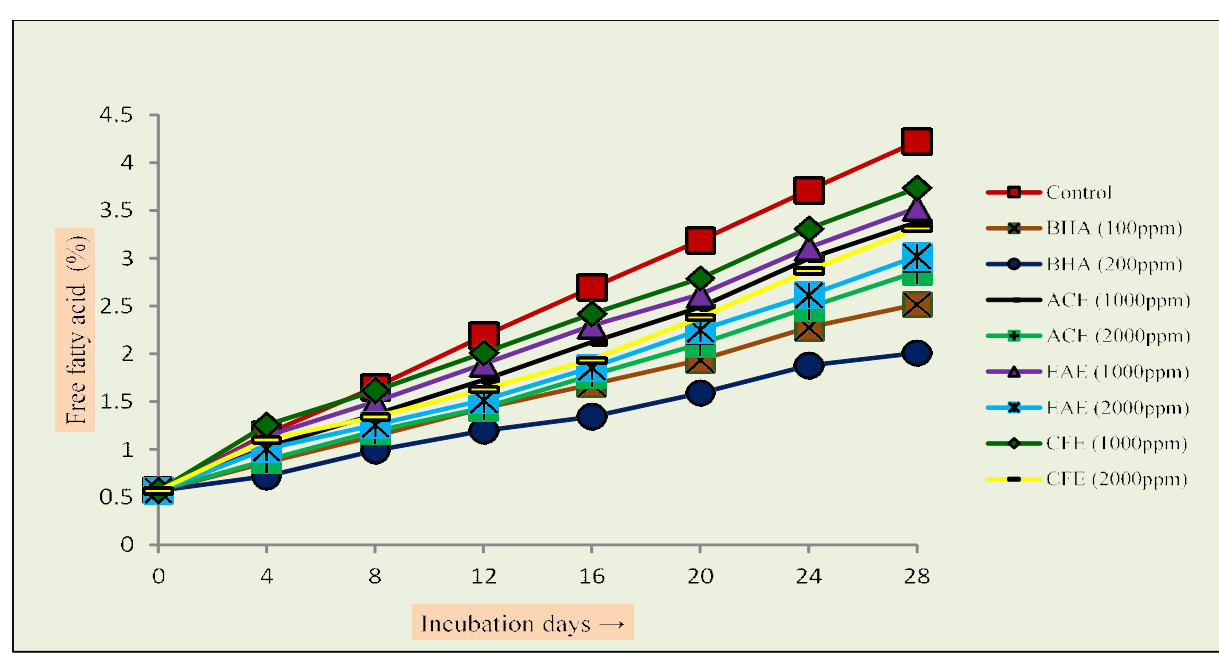

Fig 1: Free fatty acid content of soybean oil samples stabilised with BHA and different extracts of pod coat of cowpea.

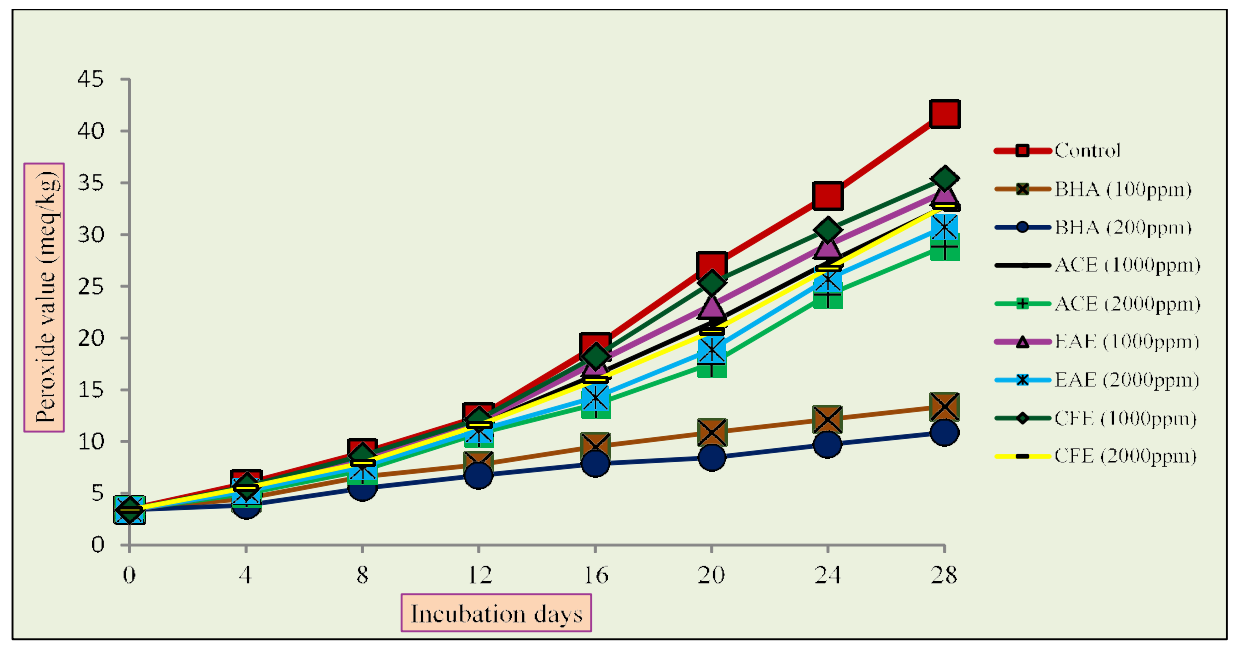

Fig 2: Peroxide values of soybean oil samples stabilised with BHA and different extracts of pod coat of cowpea.

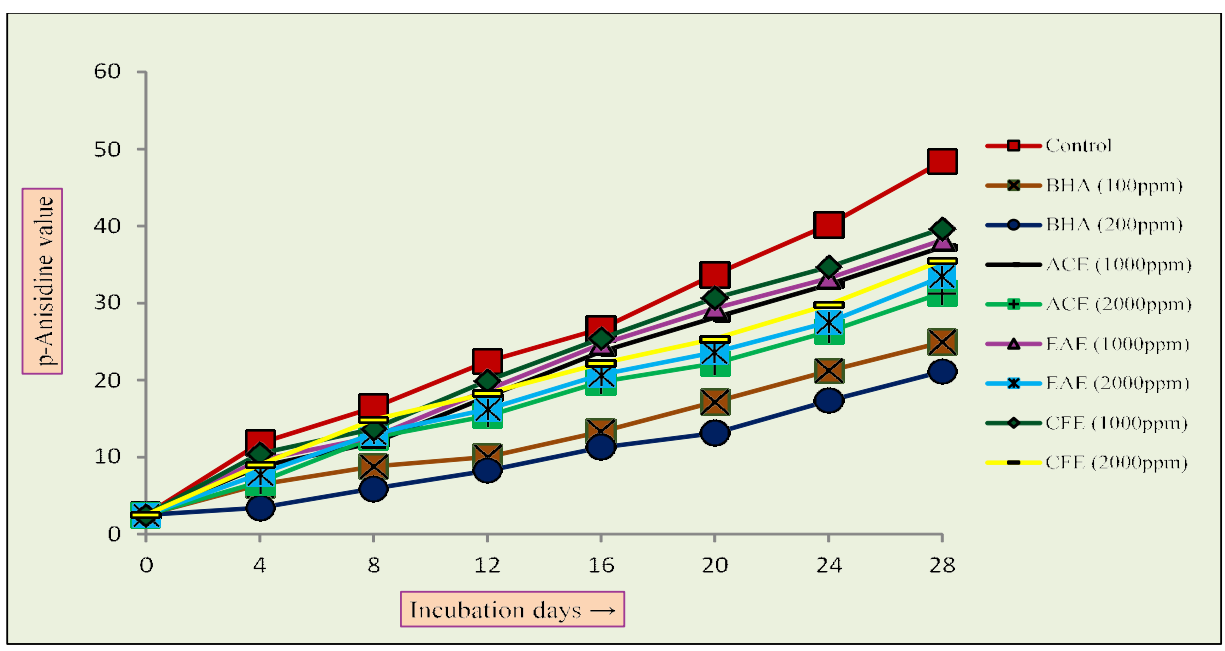

Fig 3: p-Anisidine values of soybean oil samples stabilised with BHA and different extracts of pod coat of cowpea. 
gives information about the amount of various oxidation products formed due to oxidative degradation (Erickson, 1995). AV of control increased from $2.49 \pm 0.04$ to $48.41 \pm 0.13$ during storage. AV of sample containing $\mathrm{BHA}(100 \mathrm{ppm})$ and $\mathrm{BHA}(200 \mathrm{ppm})$ was found to be $24.94 \pm 0.10$ and $21.12 \pm 0.09$ respectively at the end of storage period. Among the samples treated with various extracts, lowest AV $(31.32 \pm 0.14)$ was observed in sample containing acetone extract $(2000 \mathrm{ppm})$ while highest AV (39.68 \pm 0.10$)$ was observed in sample containing chloroform extract $(1000 \mathrm{ppm})$. Under the accelerated storage for 28 days, the total increase of $p$ Anisidine values were in the following sequence:

Control>CFE (1000 ppm)>EAE (1000 ppm)>ACE (1000 ppm) $>$ CFE (2000 ppm) > EAE (2000 ppm) >ACE (2000 ppm)>BHA (100 ppm)>BHA (200 ppm)

The higher increase of AV of samples containing extracts in comparison to those having BHA indicates the reduced capability of extracts in chelating metal ions. BHA is more effective in retarding the formation of secondary oxidation products (Michotte et al., 2011).

\section{Effects of additives on TOTOX value of soybean oil}

TOTOX values of all the samples were increasing in irregular patterns over the storage period (Fig 4). TOTOX value of control varied from $9.29 \pm 0.09$ (initially) to $131.65 \pm 0.20\left(28^{\text {th }}\right.$ day). TOTOX values of oil samples having BHA (100ppm) and BHA $(200 \mathrm{ppm})$ on the $28^{\text {th }}$ day of storage were $51.70 \pm 0.17$ and $42.84 \pm 0.19$ respectively. Among the samples treated with extracts, lowest TOTOX value $(89.04 \pm 0.20)$ exhibited by sample containing acetone extract (2000ppm) while highest value $(110.50 \pm 0.10)$ was exhibited by samples having chloroform extract (1000 ppm). Changes in TOTOX values among the samples were in following order:

Control>CFE $(1000 \mathrm{ppm})>\mathrm{EAE}(1000 \mathrm{ppm})>\mathrm{ACE}(1000$ ppm) $>$ CFE $(2000$ ppm) $>$ EAE $(2000$ ppm $)>$ ACE $(2000$ ppm $)$ $>$ BHA (100 ppm)>BHA (200 ppm)

\section{Effects of additives on Conjugated dienes (CD) and Conjugated trienes (CT) content of soybean oil}

The CD and CT values of control as well as samples supplemented with BHA or pod coat extracts during 28 days storage period is shown in Fig 5 and 6 respectively. Among the samples control had the highest CD $(36.44 \pm 0.16 \%)$ and CT $(17.36 \pm 0.06 \%)$ at the end of storage period. The higher increase in percentage of $C D$ and $C D$ during storage period indicates higher intensity of oxidation of oil sample. CD and CT values of oil samples stabilised with $\mathrm{BHA}(200 \mathrm{ppm})$ were found to be lowest i.e. $21.27 \pm 0.16 \%$ and $10.56 \pm 0.04 \%$ respectively. Among the samples containing extracts, lowest CD and CT values (29.95 \pm 0.15 and $15.42 \pm 0.09)$ were observed in samples containing acetone extract (2000 ppm) while highest $C D$ and CT values $(32.49 \pm 0.16$ and $16.94 \pm 0.08)$ were observed in sample having chloroform extract (1000 ppm). Generally the CD and CT values increase regularly with storage period as more hydroperoxide were formed which possess conjugated diene structure and more hydroperoxides degraded to secondary oxidation products with CT structures (Fishwick and Swoboda, 1977).

Conjugated dienes (\%) and conjugated trienes (\%) in different samples at the end of storage was in following order: Control>CFE $(1000 \mathrm{ppm})>\mathrm{EAE}(1000 \mathrm{ppm})>\mathrm{CFE}(2000$ ppm $)>$ ACE $(1000 \mathrm{ppm})>\operatorname{EAE}(2000 \mathrm{ppm})>\mathrm{ACE}(2000$ ppm)>BHA $(100 \mathrm{ppm})>\operatorname{BHA}(200 \mathrm{ppm})$

Effects of additives on total tocopherol content of soybean oil

Tocopherols are sensitive to light due to its conjugated triene structure and reacts irreversibly with singlet oxygen to form tocopherol hydroperoxydienone, tocopheryl quinone and quinine epoxide (Choe and Min, 2005). Tocopherols content $(\mathrm{mg} / 100 \mathrm{~g})$ in control as well as oil samples stabilized with BHA and pod coat extracts is shown in Fig 7. Tocopherol content in control at the end of storage period was

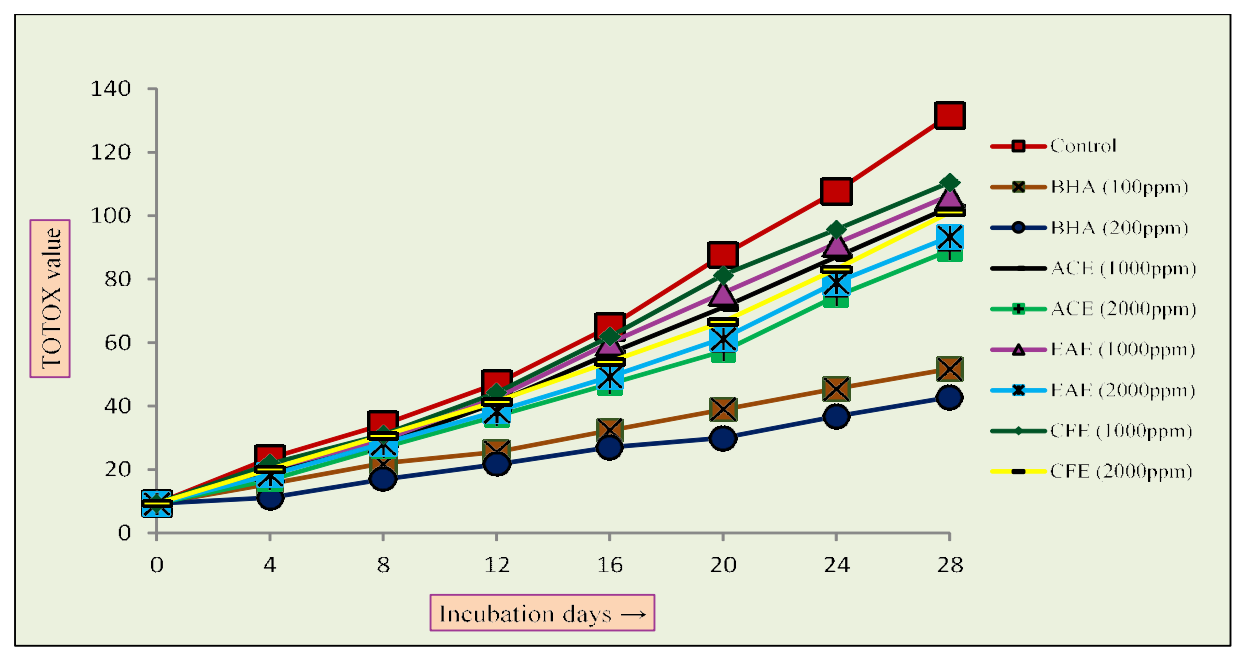

Fig 4: TOTOX values of soybean oil samples stabilised with BHA and different extracts of pod coat of cowpea. 


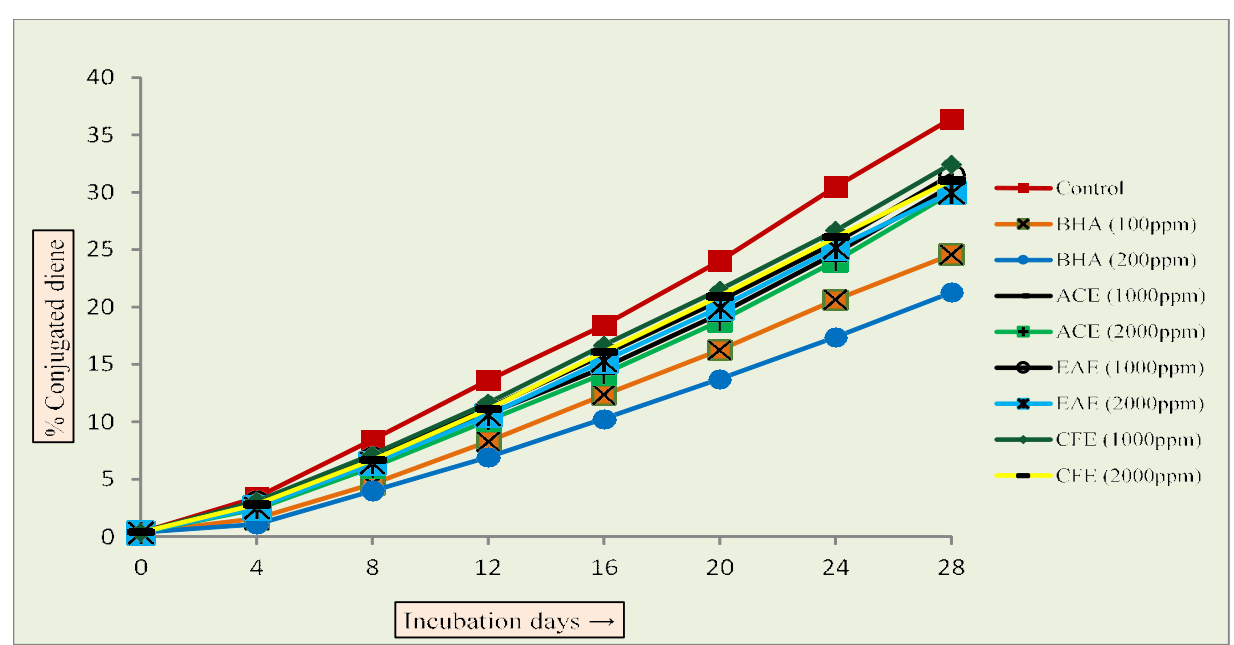

Fig 5: Conjugated dienes (\%) in soybean oil samples stabilised with BHA and different extracts of pod coat of cowpea.

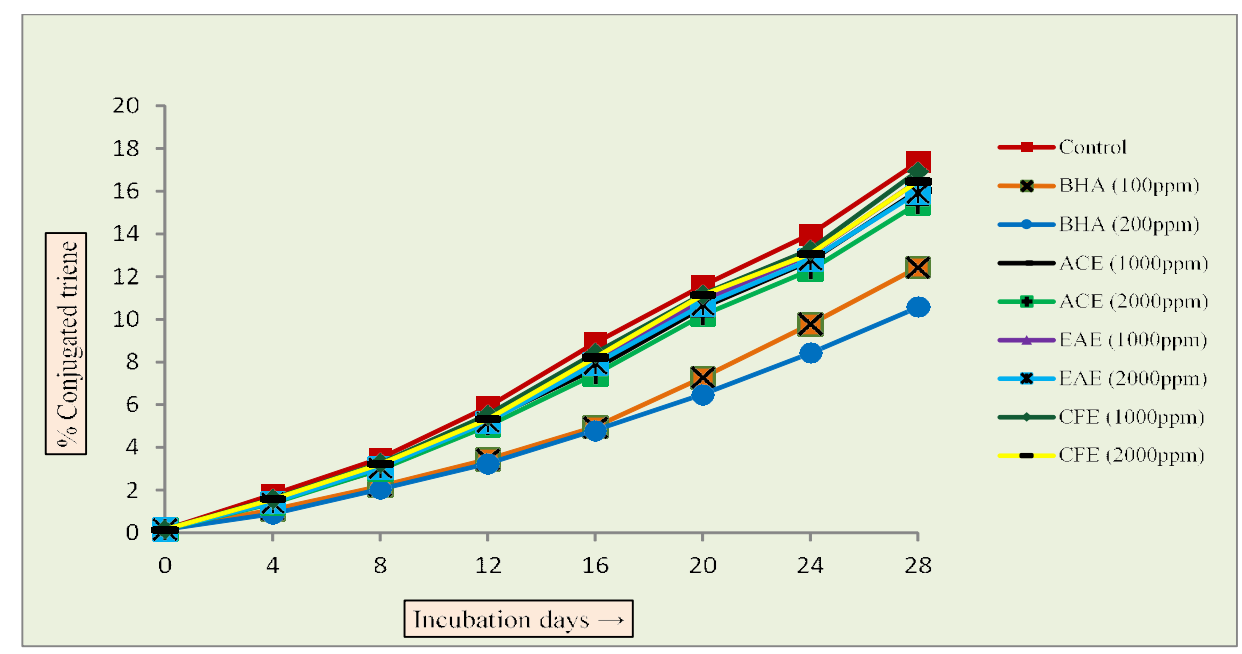

Fig 6: Conjugated trienes (\%) in soybean oil samples stabilised with BHA and different extracts of pod coat of cowpea

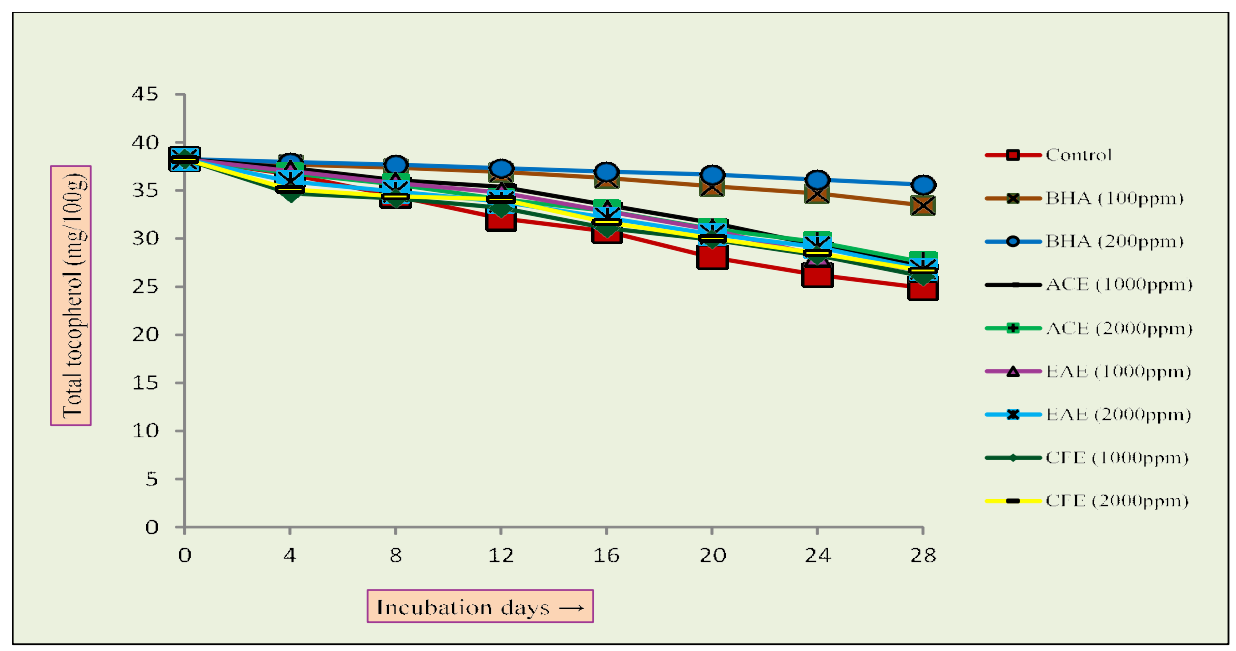

Fig 7: Tocopherols content of soybean oil samples stabilised with BHA and different extracts of pod coat of cowpea 
$24.87 \pm 0.05 \mathrm{mg} / 100 \mathrm{~g}$. Samples having BHA (100 ppm) and BHA (200ppm) had higher tocopherol content at end of storage i.e. $33.47 \pm 0.05$ and $35.61 \pm 0.08 \mathrm{mg} / 100$ respectively. Among the different samples containing extracts, tocopherol content at the end of storage period was highest $(27.56 \pm 0.06)$ in sample having acetone extract $(2000 \mathrm{ppm})$. Tocopherol content in different samples at the end of 28 days of storage was in following order:

BHA $(200$ ppm) $>$ BHA $(100$ ppm $)>$ ACE $(2000$ ppm $)>$ ACE $(1000 \mathrm{ppm})>\mathrm{EAE}(2000 \mathrm{ppm})>\mathrm{EAE}(1000 \mathrm{ppm})>\mathrm{CFE}(2000$ ppm) $>$ CFE $(1000$ ppm $)>$ Control

\section{Effects of additives on carotenoids content of soybean} oil

Carotenoids are a group of lipid-soluble pigments containing multiple conjugated double bonds that have been shown to be effective antioxidants owing to their ability to reduce excited singlet oxygen back to its less reactive triplet state. Carotenoids can easily undergo oxidation or isomerisation (Cis-Trans) during storage and processing, thus losses colour as well as biological activity. Carotenoids content of all the samples decreased in a regular manner during storage period (Fig 8). Carotenoids content in control decreased from $30.96 \pm 0.09$ to $13.59 \pm 0.04 \mathrm{mg} / \mathrm{kg}$ during storage period. Carotenoid content in samples treated with BHA (100 ppm) and BHA (200 ppm) were found to be $21.26 \pm 0.04$ and $23.19 \pm 0.02 \mathrm{mg} / \mathrm{kg}$ respectively at the end of the storage period. Among the various samples containing extracts, highest carotenoids content $(18.87 \pm 0.05 \mathrm{mg} / \mathrm{kg}$ ) was observed in the sample containing acetone extract (2000 ppm) while lowest $(16.36 \pm 0.02 \mathrm{mg} / \mathrm{kg})$ in sample containing chloroform extract (1000 ppm). The carotenoids content of different samples at the end of storage period was in following sequences:

BHA $(200$ ppm) $>$ BHA $(100$ ppm) $>$ ACE $(2000$ ppm $)>E A E$ $(2000 \mathrm{ppm})>\mathrm{ACE}(1000 \mathrm{ppm})>\mathrm{CFE}(2000 \mathrm{ppm})>\mathrm{EAE}(1000$ ppm) $>$ CFE $(1000$ ppm $)>$ Control

\section{Effects of additives on TBA value of soybean oil}

TBA value measures the extent of lipid oxidation in terms of secondary oxidation products. TBA values of all the samples are shown in Fig 9. TBA value of all the samples shows an

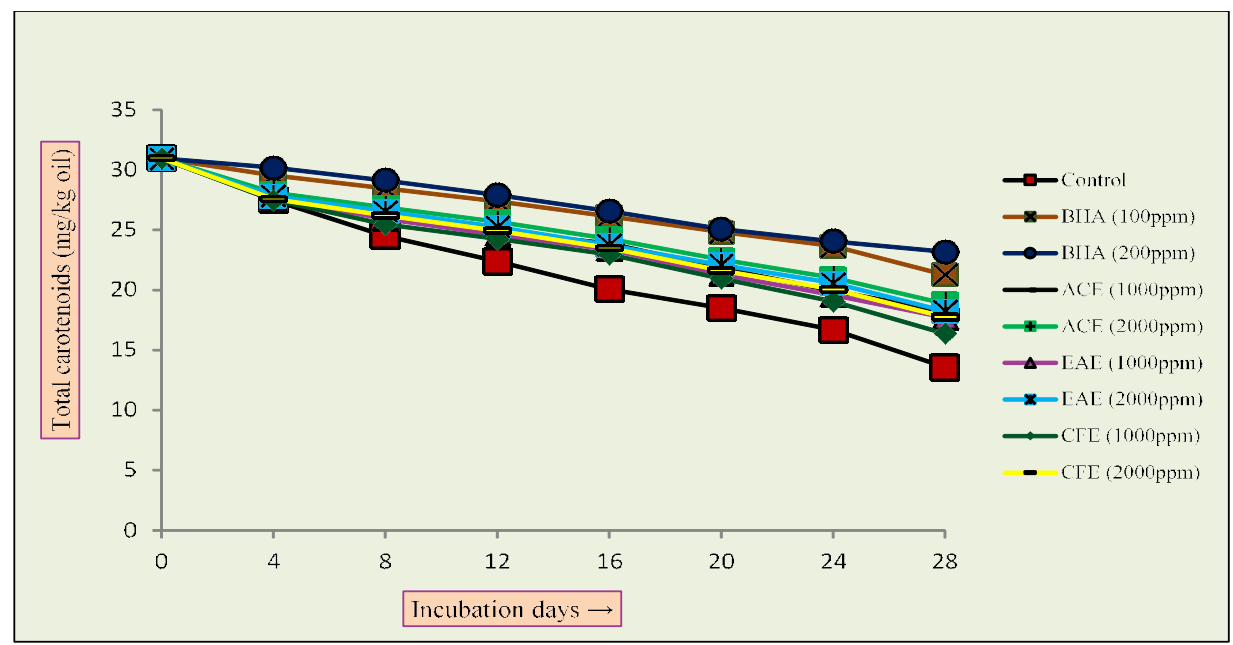

Fig 8: Carotenoids content of soybean oil samples stabilised with BHA and different extracts of pod coat of cowpea.

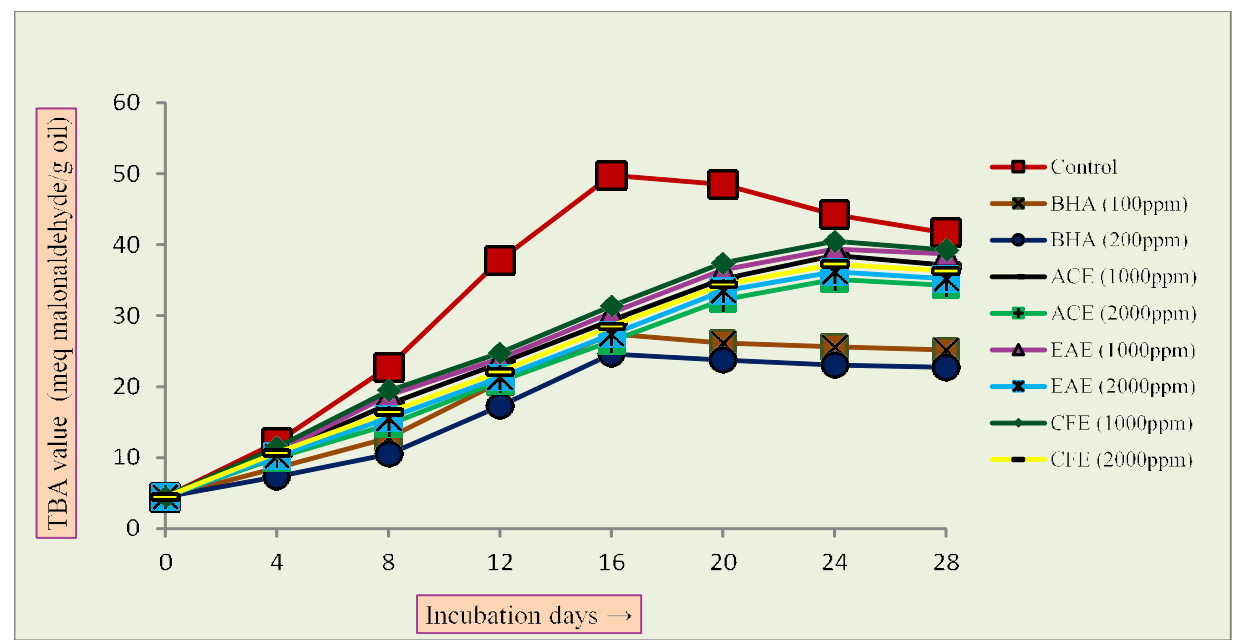

Fig 9: TBA value of soybean oil samples stabilised with BHA and different extracts of pod coat of cowpea. 
increasing trend initially, then attains a maximum value and decreases towards the end of storage period. This could be due to further oxidation of secondary oxidation products and formation of carboxylic acid (Shahidi, 2005). TBA value of control showed an increasing trend from $4.47 \pm 0.02 \mathrm{meq}$ malonaldehyde/g (at zero time) to $49.77 \pm 0.09 \mathrm{meq}$ malonaldehyde/g ( $16^{\text {th }}$ day of storage) and then started decreasing towards the end $41.67 \pm 0.17$ meq malonaldehyde/g (28 th day of storage). TBA values of samples containing BHA (100 ppm) and BHA (200 ppm) was considerably lower than all other samples throughout the storage period. TBA value of the samples stabilized with BHA (100 ppm) and BHA (200 ppm) increased from $4.47 \pm 0.02 \mathrm{meq}$ malonaldehyde/g (at zero time) to $27.44 \pm 0.08$ and $24.61 \pm 0.08 \mathrm{meq}$ malonaldehyde/g respectively (16 $6^{\text {th }}$ day of storage). TBA value of samples having $\mathrm{BHA}$ (100 and $200 \mathrm{ppm}$ ) as well as control showed an increasing trend till $16^{\text {th }}$ day of incubation however TBA value of the samples stabilized with extracts showed a longer increasing trend (till $24^{\text {th }}$ day of storage). This could be explained by slow release of phenolic compounds from extracts which results in more development of oxidation products such as malonaldehyde. TBA value of different samples at the end of storage period was in following order: Control>CFE (1000 ppm)>CFE (2000 ppm)>EAE (1000 ppm)>ACE $(1000 \mathrm{ppm})>\mathrm{EAE}(2000 \mathrm{ppm})>\mathrm{ACE}(2000$ ppm)>BHA $(100 \mathrm{ppm})>\operatorname{BHA}(200 \mathrm{ppm})$

\section{CONCLUSION}

The results of current study clearly indicated that the efficacy of BHA as well as cowpea pod coat extracts to enhance the oxidative stability of soybean oil during storage under accelerated conditions was increased by increasing the concentration of antioxidant. BHA was found to be more effective relative to pod coat extracts in stabilizing soybean oil. Among all the samples supplemented with pod coat extracts, soybean oil sample containing acetone extracts (2000ppm) showed maximum oxidative stability throughout the storage period in terms of all the parameters under study. These results prove that pod coat extracts of cowpea are capable of inhibiting lipid peroxidation in soybean oil and can be regarded as a substitute of synthetic antioxidant in edible oil industry however it is recommended that cytotoxicity of extracts under study should be investigated before their applications in vegetable oil, nutraceuticals or functional foods.

\section{REFERENCES}

American Oil Chemists' Society, (1998). Official Methods and Recommended Practices of the American Oil Chemists' Society, $5^{\text {th }}$ ed.; AOCS Press: Champaign, IL, pp 18-90.

Anwar, F., Chatha, S.A.S. and Hussain, A.I. (2007). Assessment of oxidative deterioration of soybean oil at ambient and sunlight storage. International Journal of Fats and Oils. 58(4): 390-395.
AOAC. (1990). Official Methods of Analyses. Association of Official Analytical Chemists: Washington, DC,

Awika, J.M. and Duodu, K.G. (2016). Bioactive polyphenols and peptides in cowpea (Vigna unguiculata) and their health promoting properties: A review. Journal of Functional Foods. 38: 686-697.

Choe, E. and Min, D.B. (2005). Chemistry and reactions of reactive oxygen species in foods. Journal of Food Science. 70: 142-59.

Crapiste, G.H., Brevedan, M.I.V. and Carelli, A.A. (1999). Oxidation of sunflower oil during storage. Journal of the American Oil Chemists'Society. 76: 1437. https://doi.org/10.1007/ s11746-999-0181-5.

Erickson, D.R. (1995). Practical Handbook of Soybean Processing and Utilization. $1^{\text {st }}$ edition AOCS Press, Champaign, IL, USA. pp. 292-299.

Fishwick, M.J. and Swoboda, P.A.T. (1977). Measurement of oxidation of polyunsaturated fatty acids by spectophotometric assay of conjugated derivatives. Journal of the Science of Food and Agriculture. 28: 387-393. 10.1002/jsfa.2740 280412.

Frankel, E.N. (1962). Hydroperoxides. In: Lipids and their Oxidation, [(eds.) H.W. Schultz, E.A. Day and R.O. Sinnhuber], AVI Publishing Co., Westport, CT, pp. 51-78.

Frankel, E.N. (1996). Antioxidants in lipid foods and their impact on food quality. Food Chemistry. 57: 51-55.

Marcuse, R., Johansson, L. (1973). Studies on the TBA test for rancidity grading: II. TBA reactivity of different aldehyde classes. Journal of American Oil Chemists' Society. 50: 387-391.

Mc Ginely, L. (1991). Analysis and Quality Control for Processing and Processed Fat. In: Analysis of Oilseeds Fats and Fatty Foods. [J.B. Rossel (eds.)], Elsevier Applied Science, New York, 440-470.

Michotte, D., Rogez, H., Chirinos, R., Mignolet, E., Campos, D. and Larondelle, Y. (2011). linseed oil stabilisation with pure natural phenolic compounds. Food Chemistry. 129: 1228-1231.

Mtolo, M., Gerrano, A. and Mellem, J. (2017). Effect of simulated gastrointestinal digestion on the phenolic compound content and in vitro antioxidant capacity of processed cowpea ( $V$. unguiculata) cultivars. CyTA-Journal of Food. 15: 391-399.

Philip, B., Bernard, L. and William, H. (1954). Vitamins and Deficiency Diseases. In: Practical Physiological Chemistry. New York, Toronto, London, McGraw-Hill Company, INC pp. $1272-1274$.

Rao, B.P., Rao, S.D.T. and Reddy, B.R. (1972). Rapid method for determination of free fatty acid content in fatty oil. Journal of American Oil Chemist Society. 49: 338-339.

Shahidi, F. (2005). Bailey's Industrial Oil and Fat Products. John Wiley and Sons, New Jersey.

Shahidi, F. and Wanasundara, U.N. (2008). Methods for Measuring Oxidative Stability in Edible Oils. In: Food Lipids: Chemistry, Nutrition and Biotechnology, [(eds.) C.C. Akoh and D.B. Min], CRC Press, New York, pp. 387-388.

Vasconcellous, J.A., Berry, J.W. Weber, C.W. (1980). The properties of Cucurbita foetidissima seed oil. Journal of American Oil Chemists' Society. 57: 310-313.

Young, I.S and Woodside, J.V. (2001). Antioxidants in health and disease. Journal of Clinical Pathology. 54: 176-186. 